los otros tres, entre los que se contaba el único varón, eran hijos de Diego Ruiz Lozano, un labrador casado que vivía no lejos de la casa de Isabel, en las inmediaciones de Amecameca; provincia de Chalco. La aparente contradicción entre estos datos y las declaraciones de Juana, así en su testamento como en su acta de profesión, de ser "hija legítima", puede explicarse, según el compilador, por el hecho de que su padre reconocería a los hijos de alguna manera; conducta que, dentro de las leyes españolas, pudo justificar la aseveración de Sor Juana. No debe, sin embargo, pasarse por alto que, en la "donación" a Juana, su madre se llama a sí misma "viuda" de Pedro de Asbaje, "mi esposo", y declara a Juana su "hija legítima", contradicciones que todavía reclaman una explicación satisfactoria.

También se recogen en esos documentos algunos detalles de otros parientes. Los seis hermanos parecen haberse estimado unos a otros, así como Ruiz Lozano a sus hijos ilegítimos, a quienes tanto él como su esposa legaron sus bienes. Dorothy Schons había indicado ya que una de ellas, Inés, casó con José Miguel de Torres, secretario de la Universidad de México; su hijo le sucedió en el cargo. Los hijos de Josefa María de Asbaje fueron acogidos en el seno de la familia de Francisco de Villena, notario de la ciudad de México, quien los educó, les dió su nombre e hizo de ellos sus herederos. También fué pariente de la poetisa, José Antonio de Alzate, el sabio mexicano del siglo xvrIr.

Estos documentos merecen, pues, ser cuidadosamente estudiados por quienes se interesan seriamente en conocer la vida de la más grande poetisa de Hispanoamérica, y debe felicitarse al compilador por su descubrimiento, y a la Universidad Nacional de México, por la publicación de esta obra.

Lota M. SPELL, Austin, Texas.

JosÉ MARTí, Obras completas.-Edición conmemorativa del cincuentenario de su muerte. Prólogo y síntesis biográfica por Isidro Méndez. La Habana, Editorial Lex, 1946. xxxI, 2162 y xvI, 2063 pp.

En dos volúmenes que constituyen una hazaña editorial, por la impresión nítida y la calidad del papel (siguiéndose los pasos de alguna de las ediciones realizadas por M. Aguilar en Madrid), se reúne escru- 
pulosamente la producción del escritor impar que tuvo, como pocos de los hombres extraordinarios de América, el privilegio de hacer historia y dejar gran parte de ella escrita. En el primer volumen aparecen la cartá-testamento literario de Martí, que ha servido de norma para la edición; y luego se han subdividido en cuatro partes sus escritos, agrupándolos bajo las siguientes denominaciones: Patria e independencia; Letras, Educación y Pintura (crítica y didáctica), Norteamericanos y Escenas norteamericanas. En seguida van el índice de materias formulado por Rafael Marquina y los índices onomástico y geográfico realizados por Mariano Sánchez Roca.

Ambos volúmenes - que serán de capital importancia para quienes ahondan en la obra martiana y la siguen a través de los países americanos por donde el Maestro iba aventando al voleo sus mágicas semillas-, advienen como dignísimo homenaje que se le rinde cuando aún vibran las resonancias del cincuentenario de su muerte en 1945. Después del prólogo encomendado al señor Méndez —uno de los escritores que más han estudiado la vida y la obra de Martí-, figuran páginas entresacadas de las obras de varios escritores que se han interesado en la divulgación del pensamiento martiano o que contribuyeron con especiales comentarios que solicitó de ellos el año anterior la revista Cuadernos Americanos de esta capital: Enrique José Varona, Jorge Mañach, Fernando Ortiz, Alfonso Reyes, Emeterio S. Santovenia, Juan Marinello, Gonzalo de Quesada y Miranda, Alfonso Hernández Catá, Félix Lizaso, Carlos Márquez Sterling, Luis Rodríguez Embil, José María Capo, Benjamín Jarnés, Camilo Carrancá y Trujillo, Juan Larrea y Andrés Iduarte.

En este volumen se hallan concatenados, en armoniosa integración, todos los escritos del prócer, comenzando con el que publicó en Madrid en 1861 con el título de "El presidio político en Cuba".

No estará mal insistir en la singular importancia de esta obra, para la historia de las ideas políticas y del pensamiento literario de la América española. Debe también tributarse un aplauso cálido al doctor Mariano Sánchez Roca, Director de la Editorial Lex, de La Habana, por esta hazaña que pone en sitio encumbrado a las artes gráficas cubanas.

\section{Rafael Heliodoro Valle}

